\title{
Erratum to: Diet and Diabetic Kidney Disease: Plant Versus Animal Protein
}

\author{
Ranjani N. Moorthi ${ }^{1}$ Colby J. Vorland ${ }^{2} \cdot$ Kathleen M. Hill Gallant ${ }^{2}$
}

Published online: 24 March 2017

(C) Springer Science+Business Media New York 2017

Erratum to: Curr Diab Rep (2017) 17: 15

DOI 10.1007/s11892-017-0843-x

The original version of this article unfortunately contained a mistake in the author group section. Author Kathleen M. Hill Gallant's family name was incorrectly presented as "Gallant" instead of "Hill Gallant".

The online version of the original article can be found at http://dx.doi. org/10.1007/s11892-017-0843-x

$\triangle$ Ranjani N. Moorthi

rmoorthi@iu.edu

Kathleen M. Hill Gallant

hillgallant@purdue.edu

1 Division of Nephrology, Department of Medicine, Indiana University School of Medicine, Indianapolis, IN 46202, USA

2 Department of Nutrition Science, Purdue University, 700 West State Street, West Lafayette, IN 47907, USA 